\title{
Cruising for Olivia: Lesbian Celebrity and the Cultural Politics of Coming Out in Sport
}

\author{
Megan Chawansky and Jessica Margaret Francombe \\ University of Bath
}

This paper explores issues of sport, sponsorship, and consumption by critically interrogating the mass-mediated "coming out" narratives of professional golfer, Rosie Jones, and professional basketball player, Sheryl Swoopes. Both athletes came out publicly as gay in light of endorsements received by Olivia Cruises and Resorts - a company that serves lesbian travelers - thus marking a significant shift in the relationship between lesbian subjectivity, sport, and sponsorship. A concern with a neoliberal-infused GLBT politics underscores our analysis, and a close reading of these narratives raises complex questions about the corporatization of coming out and the existence of lesbian celebrity in sport.

Cet article explore des questions de sport, de commandite et de consommation par le biais d'une interrogation critique des sorties de placard médiatisées de la golfeuse professionnelle Rosie Jones et de la joueuse de basket professionnelle Sheryl Swoopes. Les deux athlètes se sont affichées publiquement comme gaies lorsqu'elles ont fait des publicités pour la compagnie Olivia Cruises and Resorts (une entreprise qui sert les voyageuses lesbiennes), ce qui a apporté un changement important dans les relations entre la subjectivité lesbienne, le sport et les commandites. Notre analyse est marquée d'une préoccupation pour les politiques GLBT imprégnées de néo-libéralisme. Une lecture attentive des récits soulève des questions complexes au sujet de la privatisation de la sortie de placard et de l'existence des célébrités lesbiennes en sport.

Sexual stories are thus far more than individual, human-interest stories; they are cultural narratives with social and political implications (Iannotta \& Kane, 2002, p. 348).

Nearly 25 years after women's tennis legend Martina Navratilova acknowledged that she was a lesbian, two women athletes followed suit and publicly announced their gay ${ }^{1}$ identities via mainstream media publications. ${ }^{2}$ In March of 2004, veteran Ladies Professional Golf Association (LPGA) golfer Rosie Jones "came out" in a column she wrote for the New York Times sports section. Roughly

Chawansky is with Dept. of American Studies, University of Iowa, Iowa City, IA. Francombe is with the Department of Education, University of Bath, United Kingdom. 
a year and a half later, and shortly after being named the 2005 Women's National Basketball Association (WNBA) Most Valuable Player (MVP), Sheryl Swoopes used an article in ESPN The Magazine to publicly disclose her gay identity. At the time of their respective announcements, the athletes presumably had little in common besides their recently-announced gay identities; they participated in decidedly different sports, were at different stages in their athletic careers, and were of different racial backgrounds. ${ }^{3}$ However, both athletes did share recently-acquired sponsorship by Olivia Cruises and Resorts, a company that organizes luxury cruise and resort trips for lesbian travelers. More accurately, both athletes noted that the commercial endorsements from Olivia Cruises and Resorts facilitated their decisions to publicly come out as gay.

Interestingly though, the narratives suggested that both Swoopes and Jones felt somewhat disingenuous about their proclamations that Olivia helped to push them out of the proverbial closet, indicating that "getting the two celebrity personae- the 'fictional' and the 'real' - in sync" is often harder than it appears (Gever, 2003, p. 62) ${ }^{4}$ In her narrative, Jones (2004) revealed that coming out (publicly) in light of her Olivia endorsement was "a bit of a curiosity because [she's] never been in the closet” (p. 9). Similarly, in Swoopes' (2005) narrative, she recounted the responses she received after telling both her brother and her mother that she was gay, and also notes that "most of the players around the league [WNBA] already know I'm gay" (p. 126). In this analysis, then, our focus is less on Jones and Swoopes as recentlyannounced lesbian athletes, but rather on reading their narrative representations as products which reflect wider economic, cultural, and sexual norms (Birrell \& McDonald, 2000). In other words, we understand Jones' (2004) and Swoopes' (2005) mass-mediated coming out narratives as products both to be sold and used for Olivia and contend that these stories can only be consumed in a cultural context that recognizes the lesbian celebrity athlete. We focus on the ways in which these narratives suggest an important break from previously available lesbian sporting subjectivities and seek to answer this main question: Why have Swoopes' and Jones' mass-mediated coming out narratives appeared in this contemporary moment? To do this, we will first locate our discussion within previous research on lesbian sporting subjectivities. We will then review some key elements of queer theory and neoliberalism that underscore our analysis. From that point, we discuss our methodological approach and then offer contextual information on Swoopes, Jones, and Olivia Cruises. Finally, we offer our analysis of Swoopes' and Jones' narratives, and discuss the implications of our findings.

\section{Locating the Lesbian Celebrity Athlete}

One only has to consider the recent media coverage surrounding the coming out stories of Welsh rugby player, Gareth Thomas, English cricketer, Steven Davies, or the National Basketball Association's (NBA) Phoenix Suns' President and CEO, Rick Welts, to recognize that publicly-gay, high-profile sport figures still register as newsworthy. As such, though the "coming out" stories of Jones and Swoopes appeared several years ago, we nevertheless believe that it is important to further interrogate these stories because they offer an opportunity to reflect on 
the current cultural politics of coming out in sport. Moreover, they also allow us to locate the contemporary lesbian athlete within a context of professional sport. By "contemporary" we mean to suggest that Swoopes' and Jones' corporatized coming out narratives mark a decidedly different place for lesbians in sport. They speak directly to an oft-cited concern of lesbians in professional sport: athletes will lose marketing and promotional opportunities if they decide to come out publicly. To frame our research, we locate it within previous examinations of the lesbian subject in sport focusing particularly on the limited research that specifically explores the complex meanings associated with coming out in sport. King's (2008) comprehensive review of available studies of lesbian, gay, bisexual, transgender, and queer (LGBTQ) subjects within sport sociology offers a useful starting point in this process. In particular, her identification of "lesbian-centered" theorizing and her use of queer theory prove valuable in our examination of the coming out narratives of these two lesbian athletes.

Within her research, King (2008) identified "a variety of 'lesbian-centered' perspectives" which informed much of the previous research on lesbians in sport (p. 429). By using the term lesbian-centered perspectives, she meant to differentiate this body of research from those studies of gay men in sport, which impart decidedly different theoretical lenses. With this categorization, King (2008) highlighted the ways in which much previous research explored how lesbians managed their sexual identities within homophobic and heterosexist sporting environments. In essence, this research sought to understand how women existed in relation to a "code of silence" about lesbianism within women's sports (Plymire \& Forman, 2000, p. 147). These scholars used conceptual frames such as "the female apologetic" or noted the effectiveness of the "lesbian label" as they identified the real effects of a homophobic sporting context on lesbian sportswomen (King, 2008, p. 429). Further, they demonstrated the veracity of their claims largely by presenting interview data from research on coaches and athletes. According to King (2008), this type of evidence tends to occlude the discursive production of available sexual identities, an issue that is never fully resolved within this body of research. For King (2008) the lesbian-centered approaches yield two additional concerns. First, they tend to foreground identities such as "coach" and "lesbian" while overlooking other salient, intersecting identities. Second, they "reposition heterosexuality as the norm" by focusing on the presence of isolation and shame (p. 430). We heed these main concerns as we proceed in our own work on lesbians in sport.

Despite some of the aforementioned theoretical limitations within this subset of research, other work on lesbians in sport proves insightful for our own project. For instance, much of the research which examines lesbians in sport implicitly relies on the belief that larger social forces, such as mass media, contribute to the isolation and shame felt by lesbians in sport. Plymire and Forman (2000) suggested:

An open discussion of lesbians in sport is rarely, if ever, undertaken in the traditional mainstream media. Media discussions of lesbianism usually bemoan the unfair lesbian stigma that confronts heterosexual women in sport. Alternately, the media make a spectacle of lesbianism when an athlete comes out or is outed. In either case, lesbians are marginalized and the code of silence is reinforced (p. 150). 
Several scholars provide examinations of media representations of lesbians from the lesbian-centered perspectives (e.g., Lock, 2003; Wright \& Clarke, 1999). Plymire and Forman (2000), nevertheless, presented a challenge to the notion of the pervasive code of silence about lesbianism within women's sports by examining how new social media — in this case, an Internet newsgroup devoted to women's basketball-facilitates open discussion on the topic. They found that the Internet discussion threads that they studied allowed fans of women's basketball to not only break the code of silence around lesbianism in sport, but also to demonstrate the type of complex thinking about issues of gender, sexualities, and women's sport that is invisible in most mass media coverage of the topic. In much the same way, Swoopes' (2005) and Jones' (2004) mass-mediated narratives challenge the assumed code of silence around the existence of lesbians in sport. While we are less concerned with the role of media in representing Swoopes' (2005) and Jones' (2004) narratives and more interested in what the content of their narratives reveals about contemporary lesbians in professional US sport, we find this research of great relevance. Most importantly, we see our research as adding to Plymire and Forman's (2000) identification of examples wherein discussions of lesbians in women's sport can and do occur.

Of further interest to our analysis, Plymire and Forman (2000) noted that, "the contributors [to the discussion newsgroups] who came out as lesbians... wanted to discuss more than the sexual politics of women's sport. They wanted strong, positive role models to affirm their lesbian identity" (p. 151). Their desire for, and belief in the "resistive power" of increased "visibility" for lesbian athletes is not uncommon, and underscores much of early lesbian-centered research on the topic of homophobia and heterosexism in sport (King, 2008, p. 420). According to King (2008), these researchers assert that in light of the prevalence of homophobia in sport and beyond, "public declarations and enactments of nonnormative sexuality can provide much-needed inspiration and solidarity" for other similarly-situated individuals (p. 431). Indeed, this belief underscored many of the positive responses received by Swoopes and Jones. However, this premise is one that Iannotta and Kane (2002) challenge within their research on lesbians in sport:

We...critique...the theoretical approaches scholars have used to conceptualize how lesbians are "out" about their sexual identities, and what relationship these "out" identity performances have to creating tolerant, nonhomophobic sporting environments. .. Previous research has routinely privileged coming and being out linguistically — by that we mean an overt, public acknowledgment of one's sexual identity - as the most (if not the only) effective way to create inclusive and tolerant climates (p. 349).

Iannotta and Kane (2002) conducted interviews with lesbian coaches who did not identify as "publicly out," but rather employed a number of verbal and nonverbal strategies to contest homophobia and heterosexism. Their research challenged the previously-accepted belief that one must be publicly out to be an agent of change. As such, their work invariably called for further examinations into the notion of the publicly out—and subsequently politicized—lesbian, a position supported by influential scholars such as Griffin (1998) and Lenskyj (1997). Following Iannotta and Kane (2002), we critically examine the expectations of social change that accompanied Swoopes' and Jones' coming out narratives. We also present a more 
nuanced examination of lesbian visibility within Jones' (2004) and Swoopes' (2005) narratives: we seek to identify those elements of lesbian subjectivity that are visible and those that are invisible. We, similar to McDonald's (2008) examination of visibility, politics, and late capitalism within the WNBA's "Lesbians for Liberty" group, seek to make salient the larger cultural and economic forces that allowed Swoopes and Jones to publicly cruise for Olivia.

\section{Queering Lesbian-Centered Theories}

As already noted, we heed King's (2008) concerns with various lesbian-centered theories previously used in research on lesbians in sport, and therefore choose to access a queer sensibility within our own theorizing. While we do not necessarily draw from all facets of queer theory to carry out our analysis, we call upon some of its tenets to make our most important points. In this process, we find King's (2008) delineation of five key features of queer and/or queer studies especially helpful and embrace particularly three of these in our work. King (2008) suggested, for example, that queer research espouses "anti-identitarianism"(p. 421). When we claim that Jones' and Swoopes' narratives are, in part, shaped by and performed for Olivia Cruises and Resorts and not necessarily reflective of a stable, unified sense of sexual identity, we align ourselves with the notion of anti-identitarianism. In addition, queer sensitive research considers "contingency and multiplicity" when exploring the interplay of sexuality with other subjectivities (p. 425). We attend to the multiplicities of subjectivities when we reflect on how each athlete's racial and classed subjectivity manifests in her particular narrative. Finally, queer research frequently offers a "critique of heteronormativity"(p. 424).

Much of the work within queer theory already provides critiques of heteronormativity, which is the idea that heterosexuality is the coherent and privileged way of understanding sexuality. We build on this established critique by highlighting the presence of a related concept: homonormativity. Homonormativity refers to a "neoliberal politics of normalization" that uses "sameness" and an emphasis on "the rights of individuals rather than 'gay rights' in seeking 'equality' with...the mainstream" (Richardson, 2005, p. 516). The analysis of homonormativity within the sporting realm is not necessarily a new approach, and King (2009) used the lens when examining print media coverage of Swoopes' coming out announcement. King's (2009) analysis of mainstream media coverage of Swoopes' coming out announcement identified that journalists tended to explore five key themes in their writing: uncertainty over Swoopes' identity because of an earlier and highly-visible heterosexual marriage; the consequences of her announcement for the homophobic WNBA; Swoopes' deal with Olivia; the issue of homophobia within the Black community; and Swoopes' interactions with her son, Jordan, and partner/former coach, Alisa Scott. She used the concept of homonormativity to draw out how the majority of media coverage "rearticulated whiteness and economic individualism as queer norms" while exploring these main themes (p. 274). King's (2009) findings are of obvious interest to us, and we build on her earlier analysis by carefully delineating further how homonormativity comes through not only the mainstream media coverage of this announcement, but also the "first person" narratives of Jones (2004) and Swoopes (2005). 


\section{Neoliberalism}

To articulate our understanding of both athletes' narratives, we further locate our analysis within neoliberalism. This helps us comprehend how the athletes reconciled their location and participation in professional women's sports leagues not known for publicly supporting lesbian athletes or fans. ${ }^{5}$ Neoliberalism is imagined upon an epochal shift in the role of the state (Rose, 1999) "from authoritarian government to individual responsibility" (Sender, 2006, p. 135) and central to this political ideology has been the reduction of "all human action into the domain of the market" (Keddie, 2010, p. 139). Significantly, the illusion of opportunity has received much scholarly critique (Giroux, 2000; 2001; 2003a; 2004a/b/c; 2005; McMurria, 2008; Peck \& Tickell, 2002; Rose, 1999). This scholarly critique focuses predominantly upon the de-politicizing processes which work to locate social justice and welfare matters to the periphery (Keddie, 2010). We see the narratives by Jones and Swoopes as reflective of a historical present in which homonormativity is produced and maintained through capital accumulation (King, 2009), and we use Giardina's (2003) notion of "stylish hybridity" as a tool to help explain how this occurs (p. 67). For Giardina (2003), "stylish hybridity" referred to the "representations of hyphenated persons and culture(s)" which "purport[ing] to be positive, progressive artifacts subverting the status quo" but fail to deliver or challenge the "harsh realities witnessed in the everyday interactions between and among diverse segments of a population" (p. 67). Following Giardina (2003), we explicate the ways in which sexual hybridity and "difference" intersect with understandings of neoliberalism to mask the many inequalities and instances of stigmatization that resonate throughout the lesbian populous generally (e.g., McNair, 2003) and within the sporting realm specifically (e.g., Kauer, 2009). We argue, thus, that the marketability of the lesbian celebrity athlete coincides with the rise to significance of the niche gay market. In particular, it aligns with an increasingly female niche market which is visible via mediated "high class" lesbians (Himberg, 2008, p. 4). In this study we provide careful readings of Swoopes' and Jones' narratives to demonstrate that the corporatization of coming out and the emergence of lesbian celebrity in sport not only serves this new niche market but also works to obscure the ways in which hybridity and sexual "difference" still adversely impact lesbians within and outside professional sports. We now provide more details of our analysis process.

\section{Reading Texts for Dominance}

A (popular) cultural analysis such as ours expands "the tools of ideology critique to include exploring a range of sites in which the production of knowledge takes place" (Giroux, 2001, p. 14). We maintain that it is important to critically reflect on Swoopes' and Jones' coming out "moments" in light of their pedagogic potential (Giardina, 2003): what do they teach "us" about how to be lesbian athletes? Essentially, we contend that Olivia's involvement with Jones and Swoopes assists in the production of a particular knowledge(s) of how to "be" a successful lesbian athlete, and therefore, we are interested in unpacking the cultural climate and the manner through which this particular knowledge is produced. As knowledge is produced, distributed, and consumed within modes of communication (Robbins, 2009), we 
read our selected narratives to "show how the relations of power are present in the most innocent of places" (Johnson et al., 2004, p.170).

At present, only two corporatized coming out narratives from professional lesbian athletes exist, and thus our decision of which texts to analyze proved quite easy. While we only have a sample of two texts, we argue that "we can learn a lot about cultural repertoires from analysing small textual units" (Johnson et al., 2004, p.177). We followed Johnson et al.'s (2004) directive to read our texts "for dominance" which involves repeated reflection on the key contexts and understandings that emerge from our first, and then subsequent, readings and discussions of the text. For our project, the first author read through both texts to identify dominant themes. Then, through conversation and review with the second author, and several subsequent rereadings of the texts, both authors worked together to "pin down [our] key themes and...draw a picture of the presuppositions and meanings that constitute the cultural world of which the textual material is a specimen" (Peräkylä, 2005, p. 870). As our sample is small, a careful analysis is particularly important to detect the polysemic, dialogic, and contested meanings in these texts (Birrell \& McDonald, 2000). Yet, despite our careful and detailed reading we acknowledge that our analysis will be partial and politically motivated as it subscribes to the understanding that cultural studies analysis can never be anything but implicated within the social conditions on which it is premised (King, 2005, p. 28). Before presenting our findings, we offer further background on Jones, Swoopes, and Olivia to provide a context for our textual reading.

\section{Introducing Jones, Swoopes, and Olivia}

Rosie Jones joined the LPGA Tour in 1982, and was known as a steady performer and a consummate professional (Tokito, 2004) by peers and media personnel. Her op/ed piece for The New York Times (aptly titled, "First a word about me and my sponsor") appeared on March 21, 2004, and was one of the first times Jones garnered media attention in any significant way. In addition to this article in The New York Times, Jones held a news conference at a Rancho Mirage hotel during the week of the tournament to more formally announce and present her deal with Olivia (Murphy, 2004, p. D6). This press conference occurred just before the 2004 Kraft Nabisco Championship (played on the Dinah Shore Tournament Course in Rancho Mirage, California), one of the four majors on the Tour, and the one that is unofficially known as "lesbian spring break" for its reputation of attracting lesbian fans to the event and surrounding activities (Nai, 2010, II 2). While Jones' anonymity (as compared with Swoopes) perhaps necessitated a press conference, Swoopes' past accomplishments on the basketball court meant that her narrative could stand alone and still receive considerable attention. Swoopes' narrative appeared in October 2005, approximately one month after she earned her third WNBA MVP trophy. Swoopes was well known in the US before her 2005 narrative emerged; she established herself as a legitimate star in 1993 when she scored 47 points during the nationally-televised National Collegiate Athletics Association (NCAA) Division I championship game. This performance helped to bolster Swoopes' reputation as the "female Michael Jordan" and further, like Jordan, she soon had her own signature sponsorship and athletic shoe deal with Nike: the Air Swoopes. 
While Jones and Swoopes were well known within their respective leagues at the time of their announcements, Olivia Cruises and Resorts had a limited relationship with women's professional sports and with women athletes. In fact, they signed Jones, Martina Navratilova, and Swoopes as endorsers of the company in quick succession in 2004-5 (Rovell, 2005). The championing of Jones and Swoopes by Olivia Cruises and Resorts certainly made sense in terms of maximizing visibility in front of a lesbian market, and yet [then] Olivia CEO, Amy Errett, disputed any strategic marketing on the part of Olivia by saying, "[i]t has never been about getting our name in the initial announcement. But it's a logical step. We think they [Jones and Swoopes] deserve to have a company sign them who really believes in them" (Rovell, 2005, II 10). As a result, Olivia Cruises and Resorts is both present and absent in each athlete's decision to come out and within their accompanying narrative. This convenient slippage blurs the way in which the company benefits from these particular constructions. Olivia - as cultural intermediary-has been directly involved in the process, and the company, through athlete sponsorship, advertising and marketing, inevitably helps to shape identities and subjectivities.

Acting as a cultural intermediary is not necessarily a new role for Olivia which evolved from the Olivia Records collective ("an organization committed to the production, distribution and promotion of women's music") to become Olivia Cruises in 1990 (Lont, 1992, p. 245). As a collective which began in 1973, "Olivia produced about 40 albums . . . sold over a million records" and operated within a "radical lesbian feminist" sensibility (Judy's View, 2007, II 2) to produce women's music. Women's music-music "by women, for women, about women, and financially controlled by women"-adhered to a lesbian separatist mentality and sought to exist outside of mainstream music culture (Lont, 1992, p. 242). As a collective, Olivia, along with other like-minded women's music companies, aspired "to create an alternative economic institution which would employ women in a non-oppressive situation" while simultaneously reaching significant numbers of women (Lont, 1992, p. 246). Olivia's ideological vision, however, lasted only until the 1980s wherein the women's music market was overrun with albums and performers, but less so with fans interested in purchasing the work of these artists (Lont, 1992).

As a consequence, Olivia needed to find a way to merge profit-making with its politics. It created an ancillary label, the Second Wave-Olivia label (Lont, 1992) and altered its collective orientation to adopt a more hierarchical organizational structure (Martin, 1985). The company continued to expand and in 1990, Olivia Cruises began a new phase in its corporate life by taking its expertise in the production and distribution of women's music "to the water". Nearly all of Olivia Cruises foreground entertainment by lesbian musicians, (some of whom appeared on Olivia's label in the 1970s) and as the "premiere lesbian travel company," (Olivia. com, n.p.) Olivia Cruises and Resorts likely targets some of the same market that supported its records and concerts in the 1970s and 1980s. Indeed, though the price of an Olivia Cruise or Olivia Resort trip far outweighs the price of an Oliviaproduced record or concert, "most travel experts consider them some of the best travel values" (Puar, 2002, p. 944). ${ }^{6}$ As a privately-held company, it is difficult to ascertain Olivia's financial picture, but the limited information available suggests that they have found a way to merge politics and profit; in 2006, the company announced record revenues of \$20 million dollars (Weisberg, 2008). It is worth 
noting here that the record profits of 2006 occurred after Olivia Cruises made a concentrated effort to reach the lesbian sporting market by signing Jones (2004), Navratilova (2005), and Swoopes (2005). ${ }^{7}$ In the next section we indicate how each narrative helps in reaching this market via the creation of lesbian celebrity athletes.

\section{The Corporatization of Coming Out: Creating Lesbian Celebrity Athletes}

If you're a player who happens to be gay and you want to be incredibly rich, then you should come out [as gay], because it would be the best thing that ever happened to you from a marketing and an endorsement perspective.

(Dallas Mavericks' [NBA] Owner, Mark Cuban, as cited in ESPN.com, 2007)

Jones' (2004) personal narrative quite definitely frames her decision to come out as an individual and personal choice. While the actuality of coming out is, at least in part, a personal decision, Jones (2004) closes down any other possible readings of her decision to publicly come out:

I know that coming out in today's politically supercharged environment surrounding gay issues has the potential to spin into something I do not intend. I have strong feelings about gay and lesbian rights: I vote; I have my beliefs. I support causes and I support people, gay and straight, who have inspired me through the years. But first and foremost, I am a proud and blessed member of the LPGA and a professional athlete, not an activist (p. 9).

Jones directs readers to understand her narrative as purely a personal choice by foregrounding her location as an athlete first, denouncing any activist sentiment, and using a confessional, first-person tone. The focus on the personal reflects a decidedly neoliberal shift to individual responsibility. Similarly, Swoopes (2005) states that her reason for coming out is because she is "just at a point in my life where I'm tired of having to pretend to be somebody I'm not" (p. 120). Later in her narrative, Swoopes (2005) reveals the role that Olivia had in facilitating her coming out decision.

The emphasis on individuality and choice does two important things. First, it allows each athlete to be distinct from their fellow professional athletes which helps to ameliorate the likelihood that other female athletes and the leagues will be implicated (i.e., seen as "lesbian") by virtue of their announcements. ${ }^{8}$ Moreover, it allows each athlete to be accessible and consumable by others who are just like them, whether these "others" are GLBT or not. For example, Jones (2004) asks (rhetorically) in her narrative: "What professional athletes wouldn't want a lucrative relationship with a company they believed in - particularly one with a complementary social mission?" (p. 9). Through posing this question, Jones (2004) directs others to read her decision primarily in commonsense economic terms and not as a political maneuver.

Jones (2004) further downplays her lesbian identity within her narrative when she reassures readers that golf is not about politics or gay rights, but rather "golf brings people together" because "a 250-yard drive down the middle of the fairway or a long putt for birdie doesn't have a political party, a race or a sexual orientation...everything comes down to simple athletic ability, physics and the love of the 
game" (Jones, 2004, p. 9). With this statement, Jones (2004) presents an ahistorical commentary on the ways in which golf (Perkins, Mincyte \& Cole, 2010) and those who can play it still reflect class (Ceron-Anaya, 2010), race, gender, and sexual orientation divisions. As a consequence, Jones' unacknowledged white, middle class, lesbian identity is detached, disembodied, and de-politicized when it is emblazoned on Olivia merchandise and branding. ${ }^{9}$

Similar to the "Tour", the establishment of the WNBA as a sporting league made power struggles around axes of class, race, gender, and sexuality visible. For example, when the league started, Swoopes' "heterosexual" narrative was foregrounded in an attempt to thwart the association of women's sport with lesbianism by marketing it as appropriate entertainment for (heterosexual) families (McDonald, 2002).${ }^{10}$ In much of its early promotional material, the league focused on a (then) heterosexually-identified Swoopes, a fashion model/basketball player, Lisa Leslie, and "all-American" player, Rebecca Lobo (McDonald, 2002). This marketing strategy endeavored to project an image of a league filled with athletes who were accessible, grateful to their fans, and able to provide wholesome and affordable "family-oriented" entertainment (Myrdahl, 2009). In fact, the WNBA highlighted Swoopes' (heterosexual) marriage, her pregnancy, and her return to the game after giving birth to a son during the league's inaugural season to demonstrate that the league contained women who were mothers and wives as well as talented basketball players (McDonald, 2002). Therefore, her coming out narrative placed the WNBA in a precarious marketing position due to its previous reliance on Swoopes as a heterosexual and family-oriented star.

Not surprisingly then, the discernable tension between the WNBA and its lesbian athletes is never fully resolved within Swoopes' (2005) narrative, but similar to Jones (2004), the emphasis on individuality, personal responsibility, and accountability help to locate Swoopes' announcement as a personal decision and not a politicized one. Swoopes' (2005) narrative assures readers that her decision to come out after winning her third WNBA MVP award is not part of a social movement to address homophobia or inequality in sport: she is not interested in being "some sort of hero. It's [her gay identity] not something that I want to throw in people's faces" (p. 122). As such, she frames her decision to come out as an individual choice and one that she does not wish to impose on others. In terms of providing an impetus to come out, Swoopes' (2005) narrative focuses on her choice to be open about who she really is. Olivia is subsequently present and explicitly absent in Swoops' narrative: the company is mentioned but plays a seemingly minor part in the telling of her narrative. As such, a courageous lesbian sport star who can be celebrated and (financially) supported is created and the role that the league and an entire sporting institution played in keeping her "in the closet" is obscured. This narrative strategy works to effectively minimize the potential negative implications of her actions (e.g., being cut from the league or being de-emphasized in marketing material) in the larger political and social contexts wherein she and fellow (lesbian) athletes play, live, work, and love.

In stark contrast to Jones (2004), Swoopes' (2005) narrative does, at one point, attempt to consider the larger political and social contexts by discussing the significance of her race and religion in light of her coming out. Swoopes' (2005) openly acknowledges her identity as an African-American, Christian, and lesbian and the effects this might have on the reception of her coming out: 
I mean, you have Ellen [DeGeneres] . . . but you don't have your well-known gay African-American who's come out. Not to my knowledge. I know it's not accepted in the black community. I know I'll probably take a lot of flak. But in all honesty, that's not my biggest concern. My biggest concern is that people are going to look at my homosexuality and say to little girls-whether they're white, black, Hispanic - that I can't be there role model anymore. I don't want that to happen ... I'm still the same person. I'm still Sheryl. (p. 124)

Notably however, the notion that she is "still the same person. I'm still Sheryl" (Swoopes, 2005, p. 124) can be read as downplaying the significance of her race and religion as they intersect with her sexuality. As observed by King (2009), Swoopes' coming out narrative thus becomes a statement about an undifferentiated sexual identity: an identity that is partially managed because of her work both as a professional athlete and as the face of a corporate entity.

We suggest that each athlete's narrative exists as a complicated example of lesbian self-invention because, in part, it needs to reach multiple audiences. It was not just Olivia Cruises that each athlete had to "sell." Both athletes were also expected to "sell" a sporting (i.e., the WNBA and the LPGA) product that is constantly marginalized when compared with men's sporting products (Carlisle Duncan, 2006; Messner, Carlisle Duncan \& Wachs, 1996; Messner, 2002) and persistently battles with the supposed threat of a lesbian presence (Cahn, 1993; Caudwell, 2002; Lenskyj, 1995; Theberge, 2000). This is clear as both athletes seemingly defend the leagues that employ them. Jones (2004) does this by stating that she is a "proud and blessed member of the LPGA and a professional athlete" (p. 9) while Swoopes (2005) refrains from an outright critique of the WNBA and its treatment of lesbians. From our reading, both athletes were conscious of "dressing up" their narratives to appease and speak to all fans of sport as well as the professional leagues which employed them respectively.

In their coming out narratives both Jones and Swoopes devote a considerable amount of space addressing their fears that they will lose (straight) fans because of their decisions to come out. For instance, Jones (2004) addresses the fan/consumer who is not a lesbian but never explicitly acknowledges the fan(s) she might gain or the fan(s) who will likely join her on an Olivia cruise. She writes:

It is tremendously important that I consider my fans and how they may respond to this new chapter in my life. The support and the loyalty of my fans far exceeds anything I might have earned on the course. I count this as one of the true blessings in my life. The last thing I want to do is upset this balance (p. 9).

She concludes by encouraging her fans to see her "as the same competitive, hardworking Rosie I've always been" (Jones, 2004, p. 9). Similarly, Swoopes (2005) ultimately tries to reason with fans who may feel differently about her now that she has come out publicly as gay: "Being gay has nothing to do with the three gold medals or the three MVPs or the four championships I've won. I'm still the same person. I'm still Sheryl" (p. 124). Both athletes encourage their fans to see them as "the same Rosie" and "the same Sheryl"- the one that (some) fans understood to be heterosexual, and both athletes speak directly to the fans and consumers who will be unable to accept or integrate new information about their sexuality. In essence, Swoopes and Jones minimize their subjectivities as lesbian 
athletes as they invoke the previously theorized notion of "commodity lesbianism" wherein lesbian symbols, imagery, and culture are advertised to "resonate" and "reach" a lesbian consumer base without alienating heterosexual consumers (Clark, 1993, p. 181).

Despite this maneuver, we must also acknowledge that the endorsements by Olivia did allow the voices of previously silenced, "closeted" athletes and "deviant" bodies to be heard. For instance, in her narrative, Jones (2004) notes that her Olivia endorsement "represents the first time a company [like this] has sponsored a professional athlete—a gay professional athlete" (p. 9). Therefore, by virtue of her endorsement alone, she provides an example of a new, visible (albeit commerciallyinspired) lesbian athlete. Taken together then, we read Jones' and Swoopes' coming out narratives as part of the wider cultural and economic shifts associated with the move from industrial capitalism to a more "flexible capitalism" (Sender, 2006) which centralizes the demands of consumers, the autonomy of the market, and the self-realizing individual. In other words, Jones and Swoopes are products of their own making who can help sell products for Olivia (and others) because "people are rewarded...for displaying themselves in an easily-consumed public way [and by] using tropes of consumer culture" (Marwick \& Boyd, 2010, p. 119). The seemingly gay-positive narratives of Swoopes and Jones have been created by executives who have seized "the gay moment" for profitable gains (Gluckman \& Reed, 1997).

The very presence of Swoopes and Jones suggests that there has been a shift from commodity lesbianism and "gay window dressing" (Stabiner 1982, as cited in Clark, 1993, p. 183) to more direct attempts to reach the "lifestyle lesbians" (Gever, 2003, p. 39) who emerged in the 1990s. Lifestyle lesbians embraced a consumer identity which embodied "styles that [were] decidedly more spectacular and...feminized if not always conventionally feminine" (Gever, 2003, p. 39). This "type" of lesbian consumer is visible and promoted on lesbian-centered television series such as Showtime's The L Word and Bravo's reality show, Work Out, which followed the personal and professional life of openly lesbian personal trainer, Jackie Warner. As Himberg (2008) suggests, "these shows depict a certain lifestyle, and not just a lesbian one; it is an upper class one where high-end fashion, food, and bodies are the norm" (p. 3). Importantly, these shows feature women who "possess enough markers of normative femininity to look and feel familiar enough for a wide variety of women to identify with in different ways" (Reed, 2009, p. 307). When lifestyle lesbians are eager to consume and companies are eager to sell, the "lesbian celebrity" inevitably emerges (Gever, 2003, p. 6).

To Gever (2003) the concept of lesbian celebrity "is limited to instances where a celebrity is known to be and does not deny being a lesbian" and whose "stardom...is achieved and authorized within the institutions of popular culture [and is] endorsed by the mainstream media" (p. 6). At the time of her writing, Gever (2003) identified Martina Navratilova as the best example of a celebrity lesbian in light of her deliberate self-invention and re(self-)invention as she was shrouded by the celebrity-driven media's persistent interest in her sexuality. We would add Jones and Swoopes to the list of lesbian celebrities: their "ascent to sport celebrityhood is habitually reduced to individual qualities" which allow them to be understood "as [a] deserved benefactor[s]" of others' devotion and admiration (Andrews \& Jackson, 2001, p. 8). As celebrity lesbian athletes Jones and Swoopes invariably assist Olivia in reaching lifestyle lesbians consumers. 


\section{Conclusion}

We acknowledge Griffin's (1998) vision of social justice for lesbians in sport to have a choice in terms of how and when they come out publicly. Therefore, the Olivia endorsements through which Swoopes and Jones came out marks an important milestone for lesbians in sport as it presumably allowed each to come out with some degree of control and support. However, as King (2008) reminds us, "visibility does not lead automatically to the erasure of stereotypes, the end of violence, the redistribution of resources, or to greater freedom ... the effects of visibility are various and unpredictable" (p. 431). Our reading, indeed, demonstrates that Swoopes' and Jones' mediated narratives are "dressed" in individualized rhetoric of personal choice which resonates with both the lesbian and the "straight" neoliberal citizen/consumer. This, we argue, is a consequence of the silencing, the closeting and the shrouding — by economic market forces—of the voices that speak of the structural inequalities that still persist to hold up "normative" (hetero)sexuality and the emerging presence of homonormativity.

While a superficial reading of the narratives would suggest that Swoopes' and Jones' announcements "could open the door for others" (Voepel, 2005) to come out as gay and lesbian, we contend that these "positive" representations of difference, displacement, and hybridity remain always already implicated "in a universalism of the entrepreneurial spirit and the propagation of the redemptive neoliberal value of choice" (McCarthy, 2002 as cited in Giardina, 2003, p. 67). For example, a figure such as Swoopes who appropriates characteristics which can be "comfortably consumed by a predominantly White media and by White lesbian and other consumers" (King, 2009, p. 282) can perpetuate the invisibility of (certain) lesbian bodies. We demonstrated the complexity and ambiguity that shroud Swoopes' narrative as she herself contemplates and negotiates how and in what form her "new" lesbianism borders her race and religion. We also highlighted the necessity for Swoopes and Jones to appropriate a subjectivity that can be effectively "played out" in the (corporate) sports arena. The WNBA (Banet-Weiser, 1999) and the LPGA are marked by cultural configurations which delineate racialized power lines and "historically grounded racial codes continue to structure the racial formation" (Andrews, 2000, p. 166) of the leagues. The prevailing rhetoric of the leagues, nevertheless, emphasizes the disappearance of structural inequalities in favor of discourses of social mobility and (market) meritocracy (Tyler \& Bennett, 2010). We see the coming out narrative of Jones and Swoopes as parts of this rhetoric and suggest that they exist in a reinvigorated marketplace where an individualized culture breeds a climate in which identity is comprehensible when "power is uncoupled from matters of ethics and social responsibility" (Giroux, 2003b, pp. 195-6).

More specifically, we understand Jones' (2004) and Swoopes' (2005) corporatized coming out narratives to be reflective of neoliberal themes of individuality, personal responsibility, and consumerism and less about a recognizable GLBT politics. The narratives of Jones (2004) and Swoopes (2005) demonstrate the corporatization of coming out and an unfolding of a new era of lesbian celebrity in sport-an era of virtual equality wherein the illusion, as opposed to the reality, of civil rights, and equality for lesbian (athletes) exists (Vaid, 1995, p. 4). Virtual equality informs and is informed by the increasing commodification of gay and lesbian identities and the import of a gay and lesbian niche market as opposed 
to a viable political block. The conflation of visibility and a presence within the marketplace with political rights proves significant because "the capitalist market makes possible, but also constrains, social movements whose central objective is the expansion of individual political rights" (Chasin, 2000, p. XVII). As a consequence, and as a result of our analysis of the relationship between Jones (2004), Swoopes (2005), and Olivia Cruises and Resorts, the new, visible lesbian celebrity athlete requires further and ongoing interrogation.

\section{Notes}

1. Both Jones and Swoopes use the term "gay" (as opposed to lesbian) to self-identify in their coming out narratives and therefore we use it here to remain consistent with their word choice.

2. Navratilova's interactions with media regarding her sexual subjectivities prove too lengthy to summarize here. Please see Gever (2003) for a detailed account.

3. According to Tokito (2004) Jones' persistent neck injury forced her to consider "semi-retirement" in 2004. This report emerged approximately six months after her Olivia announcement. Swoopes' announcement occurred shortly after she collected her 3rd WNBA MVP trophy. She played for the WNBA's Houston Comets for 11 years, and the Seattle Storm for one year. She was waived by the Storm in 2009, and after two years away from the WNBA, she signed with the Tulsa Shock in March 2011.

4. Voepel's (2011) recent ESPN.com article on Swoopes' return to the WNBA reported that Swoopes is now involved in a romantic relationship with a man, thus adding another layer to Gever's (2003) important point on the difficulty of synchronizing the "fictional" and the "real". We would encourage future research to examine this new information about Swoopes with comparable examples of fractures within the production of celebrity personas in sport, e.g., Tiger Woods and Ryan Giggs.

5. For instance, most WNBA teams have struggled with how to market to a visible, yet mostly unacknowledged, lesbian fan base. See Myrdahl (2009). Relatedly, the LGPA has deployed specific strategies to locate their members as feminine (and presumably heterosexual) athletes. See Wolter (2010).

6. On a Rosie Jones Golf Getaway prices range from $\$ 3150$ (for a Tuscon, AZ Getaway) to $\$ 6400$ (for a 7-day Ireland Getaway; "RosieJones Golf Getaways", n.d., II 3). Cruises are priced from $\$ 1249$ (for a shared room on a Caribbean Sun Cruise) to $\$ 10,099$ for the Presidential Suite on Olivia's "Discover China Ultimate Escape". Prices available on http://www.olivia.com/.

7. Here we do not mean to imply that the lesbian "sporting market" is decidedly different from the lesbian/women's music market, but rather we wish to highlight that Olivia's endorsements of three professional athletes was a new approach to marketing their product.

8. It should be noted that at one point, Swoopes (2005) does choose to affiliate with LGBT (and other) fans who might feel empowered by her decision to come out when she acknowledges the presence and support of other lesbians within the WNBA. Swoopes (2005) speaks of the "sisterhood" which lesbian athletes in the league share (p. 125). However, fearful of perpetuating the stereotype of the WNBA being "filled with lesbians", Swoopes quickly follows up any talk of the sisterhood by challenging the idea that the WNBA has only lesbian athletes, thus stifling any discussions on the larger culture and context that might keep her fellow WNBA colleagues from publicly coming out.

9. Giroux (2003) informs our understanding of Jones as an empty signifier when he writes of an "allpowerful market" in which corporate culture and those celebrated bodies that populate it become removed of an "ethical referent", and instead aim to fulfill the needs of consumer culture (p. 7).

10. The LPGA demonstrated similar concerns about association of lesbianism within their league. See Crosset (1995) and Wolter (2010). 


\section{References}

Andrews, D.L. (2000). Excavating Michael Jordan's blackness. In S. Birrell \& M.G. McDonald (Eds.), Reading sport (pp. 166-205). Boston: Northeastern University Press. Andrews, D., \& Jackson, S. (2001). Sport stars. London: Routledge.

Banet-Weiser, S. (1999). Hoop dreams: Professional basketball and politics of race and gender. Journal of Sport and Social Issues, 23(4), 403-420.

Birrell, S., \& McDonald, M.G. (2000). Reading sport. Boston: Northeastern University Press.

Cahn, S.K. (1993). From the "muscle moll" to the "butch ball player": Mannishness, lesbianism, and homophobia in U.S. women's sport. Feminist Studies, 19(2), 343-368.

Carlisle Duncan, M. (2006). Gender warriors in sport: Women and the media. In A.A. Raney \& J. Bryant (Eds.), Handbook of sports and media (pp. 247-269). Mahwah, N.J.: Lawrence Erlbaum Associates.

Caudwell, J. (2002). Women's experiences of sexuality within football contexts: A particular and located footballing epistemology. Football Studies, 5(1), 24-45.

Ceron-Anaya, H. (2010). An approach to the history of golf: Business, symbolic capital, and technologies of the self. Journal of Sport and Social Issues, 34(3), 339-358.

Chasin, A. (2000). Selling out: The gay and lesbian movement goes to market. New York: St. Martin's Press.

Clark, D. (1993). Commodity lesbianism. In H. Abelvoe, M. Barale, \& D.M. Halperin (Eds.), The lesbian and gay studies reader (pp. 186-201). New York: Routledge.

Crosset, T. (1995). Outsiders in the clubhouse: The world of women's professional golf. Albany: SUNY Press.

ESPN.com. (2007, February 12). Cuban say openly gay player would clean up. Retrieved March 20, 2007 from: http://sports.espn.go.com/nba/news/story?id-2762656.

Gever, M. (2003). Entertaining lesbians: Celebrity, sexuality, and self-invention. New York: Routledge.

Giardina, M. (2003). "Bending it like Beckham" in the global popular: Stylish hybridity, performativity, and the politics of representation. Journal of Sport and Social Issues, 27(1), 65-82.

Giroux, H.A. (2000). Public pedagogy as cultural politics: Stuart Hall and the crisis of culture. Cultural Studies, 14(2), 341-360.

Giroux, H.A. (2001). Cultural studies as performative politics. Cultural Studies and Critical Methodologies, 1(1), 5-23.

Giroux, H. (2003a). Public space/private lives: Democracy beyond 9/11. Lanham. Rowman $\&$ Littlefield.

Giroux, H. (2003b). Spectacles of race and pedagogies of denial: Anti-black racist pedagogy under the reign of neoliberalism. Communication Education, 52(3/4), 191-211.

Giroux, H. (2004a). War on terror. The militarising of public space and culture in the United States. Third Text, 18, 211-221.

Giroux, H. (2004b). The terror of neo-liberalism. Authoritarianism and the eclipse of democracy. London: Paradigm Publishers.

Giroux, H. (2004c). Cultural studies, public pedagogy, and the responsibility of intellectuals. Communication and Critical Cultural Studies, 1(1), 59-79.

Giroux, H.A. (2005). The terror of neoliberalism: Rethinking the significance of cultural politics. College Literature, 32(1), 1-19.

Gluckman, A., \& Reed, B. (1997). The gay marketing moment. In A. Gluckman \& B. Reed (Eds.), Homo economics: Capitalism, community and lesbian and gay life (pp. 3-10). New York: Routledge.

Griffin, P. (1998). Strong women, deep closets: Lesbians and homophobia in sport. Champaign, IL: Human Kinetics.

Himberg, J. (2008). Lesbian 'femininity' on television. Thinking Gender Papers, UCLA Center for the Study of Women. Retrieved September 25, 2010 from http://escholarship.org/uc/item/48v69502 
Iannotta, J.G., \& Kane, M.J. (2002). Sexual stories as resistance narratives in women's sports: Reconceptualizing identity performance. Sociology of Sport Journal, 19, 347-369.

Johnson, R., Chambers, D., Paghuram, P., \& Ticknell, E. (2004). The practice of cultural studies. London, UK: Sage.

Jones, R. (2004, March 21). First, a word about me and my sponsor. The New York Times, p. 9. Retrieved May 10, 2006, from the LexisNexis database.

Judy's view. (2007). Retrieved December 3, 2010 from http://www.olivia.com/Connect/ Voices/judy_s_view/archive/2007/08/01/Olivia-Back-Then.aspx

Kauer, K.J. (2009). Queering lesbian sexualities in collegiate sporting spaces. Journal of Lesbian Studies, 13(3), 306-318.

Keddie, A. (2010). Neo-liberalism and new configurations of global space: Possibilities, tensions and problematic for gender justice. Journal of Gender Studies, 19(2), 139-152.

King, S. (2005). Methodological contingencies in sports studies. In D.L. Andrews, D.S. Mason, \& M. Silk (Eds.), Qualitative methods in sport studies (pp. 21-38). Oxford: Berg.

King, S. (2008). What's queer about (queer) sport sociology now? A review essay. Sociology of Sport Journal, 25, 419-442.

King, S. (2009). Homonormativity and the politics of race: Reading Sheryl Swoopes. Journal of Lesbian Studies, 13(3), 272-290.

Lenskyj, H.J. (1995). Sport and the threat to gender boundaries. Sporting Traditions, 12(1), 47-60.

Lenskyj, H.J. (1997). No Fear? Lesbians in sport and physical education. Women's Sport and Physical Activity Journal, 6(2), 7-22.

Lock, R. A. (2003). The doping ban: Compulsory heterosexuality and lesbophobia. International Review for the Sociology of Sport, 38, 397-411.

Lont, C.M. (1992). Women's music: No longer a small private party. In R. Garofalo (Ed.), Rockin' the boat: Mass music and mass movements (pp. 241-253). Boston, MA: South End Press.

Marwick, A.E., \& Boyd, D. (2010). I tweet honestly, I tweet passionately: Twitter users, context collapse and the imagined audience. New Media \& Society, 13(1), 114-133.

Martin, T. (1985). Olivia Records. Making Tracks, 58-9. Retrieved March 28, 2011 from http://www.queermusicheritage.us/olivia7.html

McDonald, M. (2002). Queering whiteness: The peculiar case of the Women's National Basketball Association. Sociological Perspectives, 45(4), 379-396.

McDonald, M. (2008). Rethinking resistance: The queer play of the Women's National Basketball Association, visibility politics and late capitalism. Leisure Studies, 27(1), 77-93.

McMurria, J. (2008). Desperate citizens and good Samaritans. Neo-liberalism and makeover reality tv. Television \& New Media, 9(4), 305-332.

McNair, R.P. (2003). Lesbian health inequalities: A cultural minority issue for health professionals. The Medical Journal of Australia, 178(12), 643-645.

Messner, M. (2002). Taking the field: Women, men, and sports. Minneapolis: University of Minnesota Press.

Messner, M., Carlisle Duncan, M., \& Wachs, F.L. (1996). The gender of audience building: Televised coverage of women's and men's NCAA basketball. Sociological Inquiry, $66(4), 422-440$.

Murphy, B. (2004, March 25). Nabisco Notebook; Golfers unfazed at Jones' coming-out. The San Francisco Chronicle, p. D6. Retrieved May 26, 2006, from the LexisNexus database.

Myrdahl, T.K.M. (2009). "Family Friendly" without the double entendre: A spatial analysis of normative game spaces and lesbian fans. Journal of Lesbian Studies, 13(3), 291-305.

Nai, D. (2010). Out in the Desert: blows the lid off the Dinah Shore Weekend. Retrieved December 3, 2010 from http://www.afterellen.com/blog/daranai/out-in-the-desertblows-the-lid-off-the-dinah-shore-weekend

Olivia.com. (n.d.). Retrieved May 20, 2011 from http://www.olivia.com/ 
“Olivia Back Then”. (2007). Retrieved December 1, 2010 from http://www.olivia.com/ Connect/Voices/judy_s_view/archive/2007/08/01/Olivia-Back-Then.aspx

Peck, J., \& Tickell, A. (2002). Neo-liberalizing space. Antipode, 34(3), 380-404.

Peräkylä, A. (2005). Analyzing talk and text. In N.K. Denzin \& Y.S. Lincoln (Eds.), The Sage handbook of qualitative research (3rd ed., pp. 869-881). Thousand Oaks: Sage.

Perkins, C., Mincyte, D., \& Cole, C.L. (2010). Making the critical links and the links critical in golf studies: Introduction to special issue. Journal of Sport and Social Issues, 34(3), 267-271.

Plymire, D.C., \& Forman, P.J. (2000). Breaking the silence: Lesbian fans, the Internet, and the sexual politics of women's sport. International Journal of Sexuality and Gender Studies, 5(2), 141-153.

Puar, J. (2002). A transnational feminist critique of queer tourism. Antipode, 34(5), 935-946.

Reed, J. (2009). Lesbian television personalities-A queer new subject. Journal of American Culture, 32(4), 307-317.

Richardson, D. (2005). Desiring sameness? The rise of a neoliberal politics of normalisation. Antipode, 37(3), 516-535.

Robbins, C.G. (2009). Searching for politics with Henry Giroux: Through cultural studies to public pedagogy and the "terror of neoliberalism". Review of Education, Pedagogy \& Cultural Studies, 21, 429-278.

Rose, N. (1999). Governing the soul: The shaping of the private self. London: Free Associations Books.

RosieJones Golf Getaways. (n.d.) Retrieved September 25, 2010 from http://www.rosiejones. com/index.php/golf-getaways/

Rovell, D. (2005, October 26). Swoopes' coming out has tie-in to endorsement deal. Retrieved April 11, 2005 from http://sports.espn.go.com/espn/news/story?id=2204456

Sender, K. (2006). Queens for a day: Queer eye for the straight guy and the neoliberal project. Critical Studies in Media Communication, 23(2), 131-151.

Swoopes, S. (2005, October 26). Outside the Arc. ESPN The Magazine, 120-5.

Theberge, N. (2000). Gender and sport. In J.J. Coakley \& E. Dunning (Eds.), Handbook of sports studies (pp. 322-343). London: Sage.

Tokito, M. (2004, September 12). Neck injury has Rosie Jones facing a life with less golf. The Oregonian. 6. Retrieved from LexisNexis database.

Tyler, I., \& Bennett, B. (2010). 'Celebrity chav': Fame, femininity and social class. European Journal of Cultural Studies, 13(3), 375-393.

Vaid, U. (1995). Virtual Equality: The mainstreaming of gay and lesbian liberation. New York: Anchor Books, Doubleday.

Voepel, M. (2005, October 25). Swoopes could open door for others to follow. Retrieved October 26, 2005, from http://sports.espn.go.com/espn/print?id=2203893\&type=story

Voepel, M. (2011). Swoopes, 40, as passionate as ever. Retrieved July 20, 2011 from http:// sports.espn.go.com/wnba/columns/story?columnist=voepel_mechelle\&i d=6732292

Weisberg, J. (2008, February 26). Olivia Cruises: Out to Sea. The Advocate. Retrieved March 28, 2011 from http://www.advocate.com/Business/Olivia_Out_to_Sea/

Wolter, S. (2010). The Ladies Professional Golf Association's five points of celebrity: 'Driving' the organization 'fore-ward' or a snap-hook into the next fairway? International Journal of Sport Communication, 3, 31-48.

Wright, J., \& Clarke, G. (1999). Sport, the media and the construction of compulsory heterosexuality: A case study of women's rugby union. International Review for the Sociology of Sport, 34, 227-243. 